\title{
Vaccine-Induced Immune Thrombotic Thrombocytopenia after Receiving the ChAdOx1 nCoV-19 Vaccine
}

Ambika Tejpal ${ }^{1}$, Peter Economopoulos ${ }^{2}$, Roseann Andreou, ${ }^{2}$ and James Stevenson ${ }^{1}$

${ }^{1}$ University of Toronto, Toronto, ON, Canada ${ }^{2}$ Michael Garron Hospital, Toronto, Ontario

Author for correspondence: ambika.tejpal@medportal.ca

Received: 4 May 2021; Accepted after revision: 12 May 2021; Published: 21 June 2021

DOI: https://doi.org/10.22374/cjgim.v16i2.559

\begin{abstract}
Vaccine-induced prothrombotic immune thrombocytopenia (VIPIT) is a rare complication noted after immunization against coronavirus disease with the ChAdOx1 nCoV-19 (AstraZeneca) vaccine. Here we report such a case in a 61-year-old gentleman who presented twenty days after receiving the vaccine and was diagnosed with massive bilateral pulmonary emboli with a saddle embolus. This is the third such case in Canada. This case serves to highlight that venous thromboembolism in an older, male patient presenting in a typical manner can still be VIPIT, despite reports of this occurring predominantly in young females with intracranial and splanchnic thromboses. It is important to make the diagnosis accurately and in a timely fashion because the management strategy differs from that of classic venous thromboembolism. Heparin anticoagulants should be avoided, and intravenous immunoglobulin is critical to consider as part of the treatment.
\end{abstract}

\section{Résumé}

La thrombocytopénie thrombotique immunitaire induite par le vaccin (TTIV) est une complication rare, signalée après l'immunisation contre la maladie à coronavirus par le vaccin ChAdOx1 nCoV-19 (AstraZeneca). Cet article expose le cas d'un homme de 61 ans qui sest présenté à l'hôpital 20 jours après avoir reçu le vaccin et a reçu un diagnostic d'embolie pulmonaire bilatérale massive avec une embolie en selle. Il s'agit du troisième cas du genre au Canada. Ce cas vient démontrer qu'un homme plus âgé qui présente les symptômes typiques d'une thromboembolie veineuse peut être atteint d'une TTIV, même si l'on rapporte quelle survient essentiellement chez les jeunes femmes atteintes de thromboses intracrâniennes et splanchniques. Il est important de poser le diagnostic rapidement et avec précision, car la stratégie de prise en charge de la TTIV diffère de celle de la thromboembolie veineuse classique. Les anticoagulants à base d'héparine doivent être évités, et il est essentiel de considérer l'administration d'immunoglobulines par voie intraveineuse dans le cadre du traitement. 


\section{Case Presentation}

A 61-year-old gentleman presented to hospital with back pain twenty days after the ChAdOx1 nCoV-19 (AstraZeneca) vaccine. His past medical history was significant for hypertension, dyslipidemia, coronary artery disease, obstructive sleep apnea, total hip arthroplasty two years ago, prior transurethral resection of the prostate, and spinal stenosis. His medications included telmisartan, rosuvastatin, bisoprolol, aspirin, clopidogrel, pantoprazole, and nabilone. His blood work was notable for new thrombocytopenia with a platelet count of $71 \times 10^{9} / \mathrm{L}$. His last complete blood count nine months earlier was normal, with a platelet count of $183 \times 10^{9} / \mathrm{L}$. He had no prior history of thrombocytopenia. He was discharged home with ketorolac for musculoskeletal pain. He re-presented again six days later with mechanical back pain and blood work notable for a platelet count of $81 \times 10^{9} / \mathrm{L}$. He returned to hospital again three days later with shortness of breath, hemoptysis, and presyncope. Blood pressure was $128 / 79$, heart rate 90 beats per minute, and oxygen saturation $94 \%$ on room air. He had no calf pain or edema. Blood work was significant for a high sensitivity troponin- $\mathrm{T}$ of $134 \mathrm{ng} / \mathrm{L}$, and his platelet count was $134 \times 10^{9} / \mathrm{L}$. His D-dimer was greater than 6000 $\mathrm{mcg} / \mathrm{L}$, international normalized ratio 1.2, partial thromboplastin time 29 seconds, and fibrinogen $3.45 \mathrm{~g} / \mathrm{L}$. Electrocardiogram revealed new T-wave inversions in the anterior leads (Figure 1). Chest computed tomography (CT) revealed massive bilateral pulmonary emboli with a saddle embolus (Figure 2).

The patient had no history of immobilization, recent surgery, malignancy, weight loss, fever, or night sweats, he was up to date with cancer screening, and there was no personal or family history of thrombosis. He had no features of deep vein thrombosis, and he was never tachycardic. His first dose of the ChAdOx1 nCoV-19 vaccine was four weeks before the current presentation. He had no prior history of heparin exposure. He received one dose of therapeutic dalteparin. Given his lack of risk factors, except for his recent vaccination with the AstraZeneca vaccine, there was a concern for vaccine-induced immune thrombotic thrombocytopenia (VITT). Dalteparin was therefore discontinued, and he was transitioned to apixaban. A heparin-induced thrombocytopenia (HIT) assay was positive with an optical density of 1.23 . His serotonin release assay was also positive. He had no headache or neurologic symptoms, and CT venogram of the brain was normal. He had bilateral Doppler ultrasounds of his lower extremities and was diagnosed with acute right leg deep venous thrombosis, causing occlusion of the right middle and distal popliteal vein, peroneal and posterior tibial veins. He was treated with intravenous immunoglobulin

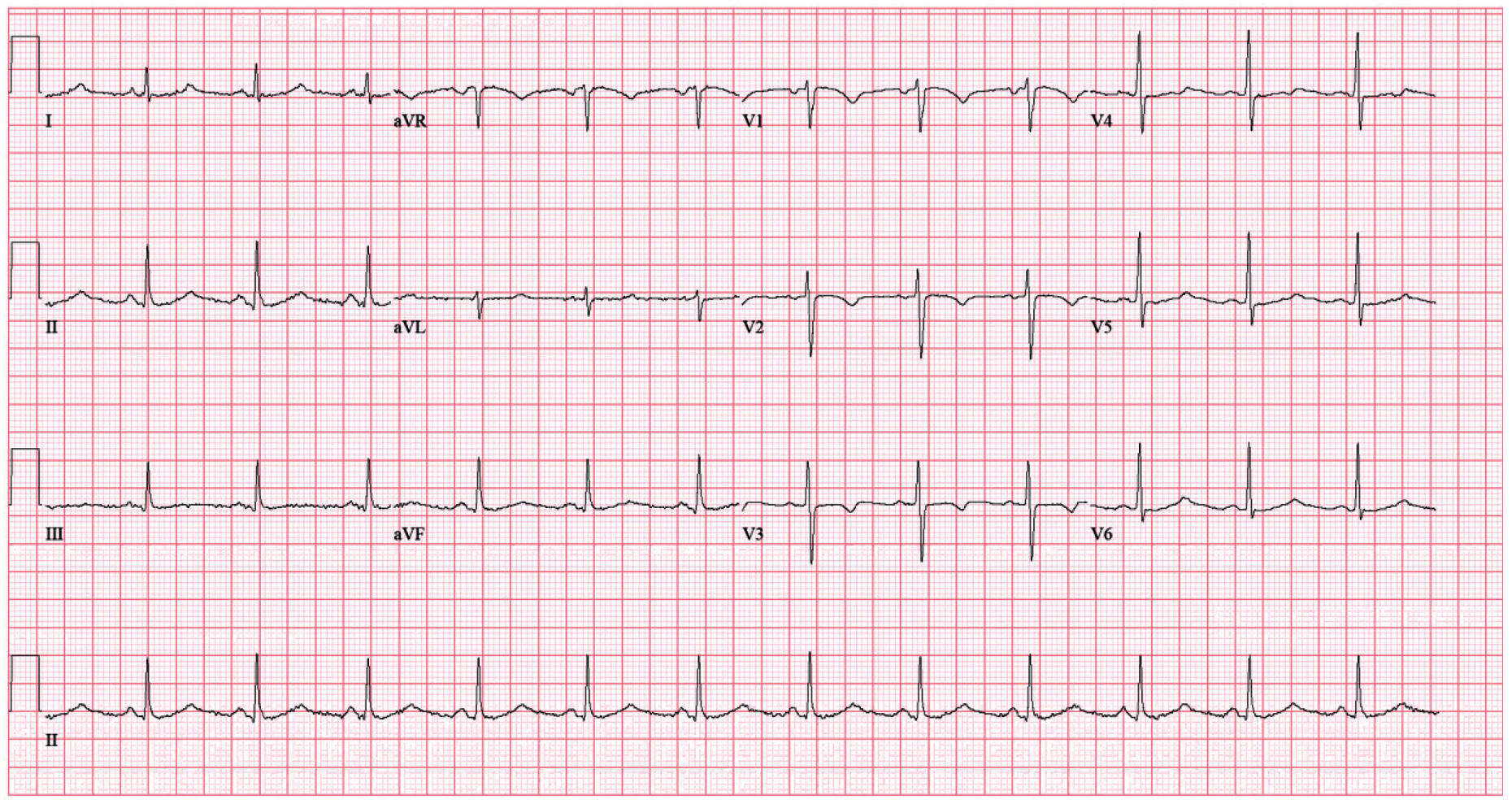

Figure 1. Electrocardiogram showing new T-wave inversions in the anterior leads. 


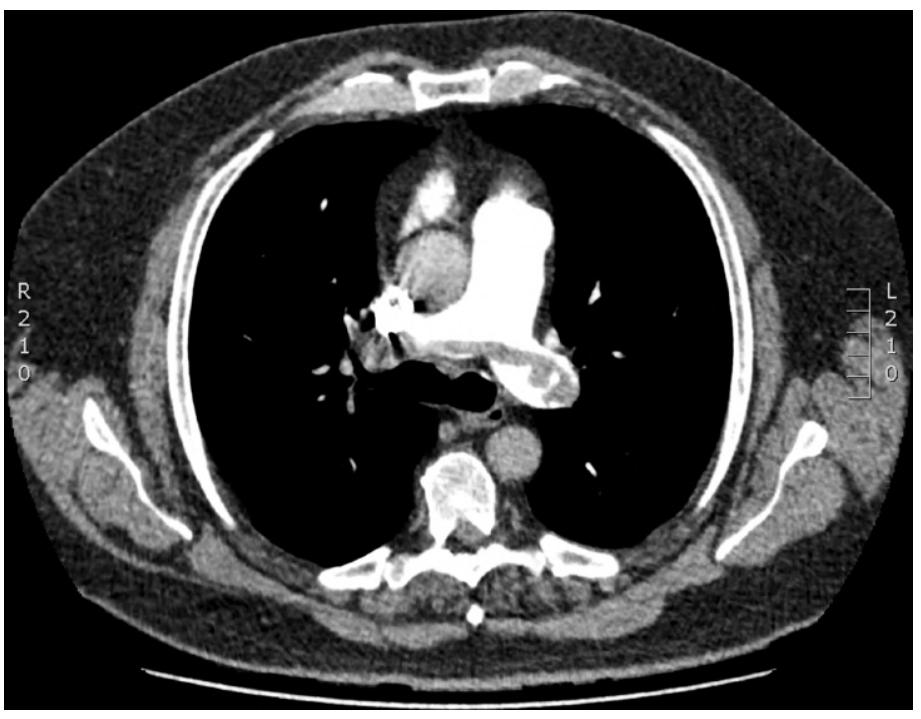

Figure 2. CT Chest pulmonary embolism protocol showing saddle embolus.

(IVIG) $1 \mathrm{~g} / \mathrm{kg}$ for two days. His clinical status improved, as did his platelet count, $261 \times 10^{9} / \mathrm{L}$ upon discharge home five days later.

\section{Discussion}

VITT is a rare complication of the ChAdOx $1 \mathrm{nCoV}-19$ vaccine and was estimated to occur in $1 / 100,000$ patients. ${ }^{1}$ To date only two other cases of VITT have been reported in Canada, however as mass vaccination of COVID-19 rolls out in Canada, more cases of VITT are anticipated in the coming months. A high index of suspicion is required to diagnose VITT as it is not associated with traditional risk factors for thromboembolism. Symptom onset is typically between six and twenty days after vaccine exposure, and unexplained thrombocytopenia can be a clue in the diagnosis of VITT and should prompt further investigation in the right host. ${ }^{2}$

VITT is most often reported in younger females with thrombosis at unusual sites such as the splanchnic and cerebral veins. ${ }^{3}$ In a case series of eleven patients with thrombotic events and thrombocytopenia after inoculation with a viral vector vaccine against COVID-19, Greinacher et al. found that pulmonary embolism was a feature of only three patients. ${ }^{4}$ Nine patients were found to have cerebral venous sinus thrombosis, three had splanchnic-vein thrombosis, and five had other various forms of thromboses. ${ }^{4}$ Schultz et al. studied five patients with this complication, none of whom had pulmonary embolism as the location of venous thrombosis. ${ }^{3}$ Our case, however, was in a middle-aged male with a massive pulmonary embolus. Similarly, despite the propensity for younger patients and atypical thrombosis in VITT, in a case series of twenty-three patients with VITT reported by Scully et al., six patients had pulmonary embolism, and cases were reported in patients up to 77 years of age. ${ }^{2}$

The pathophysiology of VITT is thought to be immunemediated through platelet-activating antibodies against platelet factor 4 (PF4), similar to $\mathrm{HIT}^{2} \mathrm{HIT}$ is a complication that results from exposure to heparin that results in the formation of IgG antibodies against PF4 complexed with heparin. This activates Fc $\gamma$ RIIa receptors on platelets, leading to platelet activation and the release of procoagulant microparticles. ${ }^{5}$ The thrombocytopenia that ensues results from the removal of IgG-coated platelets by the reticuloendothelial syndrome and platelet consumption in thrombosis. ${ }^{5,6}$ In the case of VITT the antibodies to PF4 occur without exposure to heparin. ${ }^{2}$ Immunoassays show a strongly positive reaction on P4F-heparin ELISA in VITT and HIT. ${ }^{2-4}$

Several syndromes that resemble HIT have been reported and are collectively referred to as autoimmune HIT syndromes. These include delayed-onset HIT, persisting HIT, spontaneous HIT syndrome, flush heparin HIT, fondaparinux-associated HIT, and severe HIT with overt DIC. Spontaneous HIT syndrome is a condition in which anti-PF4-polyanion antibodies are found in the blood despite the absence of exposure to heparin. The downstream effects of this are similar to those seen in the classic form of HIT, with both thrombocytopenia and thrombosis seen in cases of spontaneous HIT. Possible triggers include viral or bacterial infections and orthopedic surgery. ${ }^{7}$ HIT antibody testing is a crucial component in evaluating suspected VITT, as the management of VITT differs from the management of typical venous thromboembolism. In particular, heparin and platelet transfusions should be avoided, and a HIT-compatible anticoagulant should be used. Specifically, options include direct oral anticoagulants, fondaparinux, danaparoid, and argatroban. ${ }^{8}$ At present, it is unclear whether heparin exacerbates this condition, but given the proposed pathophysiologic mechanism, the recommendation is to avoid heparin until further study. ${ }^{8}$ Hypofibrinoginemia has also been noted as a feature of VITT. In a study of eleven patients with VITT, 6 had fibrinogen levels measured, and four developed hypofibrinogenemia. ${ }^{4}$ Fibrinogen level monitoring is recommended, with replacement as needed.

In those with VITT and severe thrombotic disease, treatment with IVIG $1 \mathrm{~g} / \mathrm{kg}$ for two days is recommended. ${ }^{8,9}$ Prior to the identification of VITT, IVIG had been used for autoimmune HIT syndromes with good effect. ${ }^{7}$ IVIG is thought to inhibit antibody activation of platelets and lead to abrupt platelet count recovery. Although this patient originally had evidence of thrombocytopenia, the platelet count had recovered by the time of diagnosis. IVIG was still used due to the extent of the massive pulmonary embolus. Other therapeutic options to consider in refractory cases include steroids and plasma exchange, though research in this area is limited. 


\section{Conclusion}

VITT is a rare but important complication of vaccination with the ChAdOx1 nCoV-19 vaccine. A high degree of suspicion is required since thrombosis can occur up to four weeks following vaccination. While previously thought to occur in young females, with the clot location often being intracranial, our case highlights the fact that VITT can present in a variety of ways, including older men with pulmonary embolism or deep vein thrombosis. Thrombocytopenia can be an important clue to the diagnosis. Pathophysiologic mechanism and treatment remain areas of ongoing research, but the disease is thought to be mechanistically similar to HIT. In patients with suspected VITT, a HIT assay should be obtained, heparin should be avoided as the choice of anticoagulant, and IVIG should be considered.

\section{References}

1. Cines DB, Bussel JB. SARS-CoV-2 Vaccine-induced immune thrombotic thrombocytopenia. N Engl J Med. 2021 Apr 16;0(0):null.

2. Scully M, Singh D, Lown R, et al. Pathologic antibodies to platelet factor 4 after ChAdOx1 nCoV-19 vaccination. N Engl J Med. 2021 Apr 16;0(0):null.
3. Schultz NH, Sørvoll IH, Michelsen AE, et al. Thrombosis and hrombocytopenia after ChAdOx1 nCoV-19 vaccination. N Engl J Med [Internet]. 2021 Apr 9 [cited 2021 Apr 26]; Available from: https://www.nejm. org/doi/10.1056/NEJMoa2104882

4. Greinacher A, Thiele T, Warkentin TE, et al. Thrombotic thrombocytopenia after ChAdOx1 nCov-19 Vaccination. New Engl J Med [Internet]. $2021 \mathrm{Apr}$ 9 [cited 2021 Apr 26]; Available from: https://www.nejm.org/doi/10.1056/ NEJMoa2104840

5. Rauova L, Poncz M, McKenzie SE, et al. Ultralarge complexes of PF4 and heparin are central to the pathogenesis of heparin-induced thrombocytopenia. Blood. 2005 Jan 1;105(1):131-8.

6. Franchini M. Heparin-induced thrombocytopenia: an update. Thrombosis J. 2005 Oct 4;3(1):14.

7. Greinacher A, Selleng K, Warkentin TE. Autoimmune heparin-induced thrombocytopenia. J Thrombo Haemo. 2017;15(11):2099-114.

8. Oldenburg J, Klamroth R, Langer F, et al. Diagnosis and management of vaccine-related thrombosis following AstraZeneca COVID-19 vaccination: Guidance Statement from the GTH. Hamostaseologie [Internet]. $2021 \mathrm{Apr}$ 1 [cited 2021 Apr 26]; Available from: http://www.thieme-connect.de/DOI/ DOI?10.1055/a-1469-7481

9. American Society of Hematology. Thrombosis with thrombocytopenia syndrome - Hematology.org [Internet]. [cited 2021 Apr 26]. Available from: https://www.hematology.org:443/covid-19/ vaccine-induced-immune-thrombotic-thrombocytopenia 